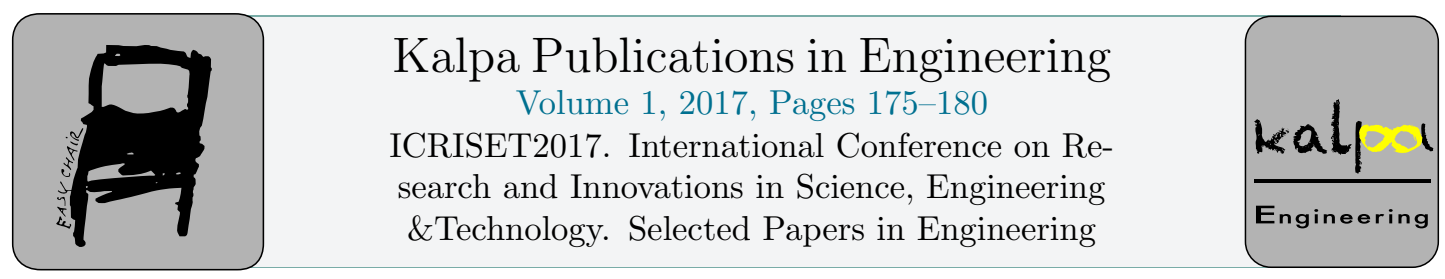

\title{
Reactive Power Compensation Using FACTS Device
}

\author{
Dhaval Desai $^{1}$ and Swapnil Arya ${ }^{2}$ \\ ${ }^{1}$ M. Tech Electrical Engineering, ${ }^{2}$ Asst Prof. Electrical Engineering \\ 1,2 BVM Engineering College, Vallabh Vidyanagar, India \\ drdesai4793@gmail.com, arya.bvm@gmail.com
}

\begin{abstract}
In this paper Matlab-simulink model of single phase variable load with Fixed Capacitor-Thyristor controlled reactor (FC-TCR) for compensation of reactive power is presented. The specific feature of proposed model is determining load reactive power instantaneously and by involving automatic control method compensate load reactive power. The model of FC-TCR and control system is presented such that it is easy to implement in hardware. Detail discussion of all the block is given. And all the results are discussed for the various load.
\end{abstract}

\section{Introduction}

Reactive power compensation has been very vital factor in designing and operation of transmission and distribution system. The modern power system becomes very complex. In the system, there are many static and dynamic devices are included. So, that automatic reactive power compensation is necessary. Apart from that a transmission line always produces VARs in proportion to the square of the voltage applied. At the same time, it also consumes VARs in proportion to the square of the current carried by it. That means consumption of VARs increases if load increases \& decreases if load decreases.

For better performance of the power system capacities by introducing compensation devices like Flexible AC Transmission system [FACTS] device becomes very important. With the introduction of FACTS device, we can do real time control of the reactive power. By using FACTS device with controller, we can deal with variable reactive power demands. Device like Fixed Capacitor Thyristor Controlled Reactor (FC-TCR) can control variable reactive power with the use of controller. The controlling of reactive power depends on the rating of the Capacitor, rating of Reactor and rating of the Switches. By controlling firing angle and pulse width of the gate pulses we can control the reactive power. 


\section{Reactive Power Compensation}

\subsection{Need of reactive power compensation}

To enable the voltage and to provide active power (watt) along transmission line reactive power is mandatory. As in the system major loads are passive loads. This passive device stores reactive power produce by the ac source in the positive quarter of cycle and it sent back to the ac power source during the next quarter of cycle. And same for the negative cycle. During this operation frequency of reactive power motion is two times the rated value. So, to avoid the circulation between the passive loads and AC power source reactive power needs to compensate. And to maintain the power factor near to unity of the system and maintain the voltage stability reactive power should compensate.

\subsection{FACTS Device}

Now for the transmission planner most important aspect is that FACTS technology opens up new opportunities for controlling power and enhancing the usable capacity of present, as well as new upgraded lines [1]. The likelihood that current through a line can be controlled at a practicable cost enables a large potential of increasing the capacity of existing line with huge conductors, and use of FACTS devices to make it possible for concur with power to flow through such lines under normal and occurrence.

\section{Model Description}

Figure. 1 represents the Simulink model being used to control the reactive power by using IGBT's for controlling the reactive power supplied by the capacitor.

Figure. 2 represents the control of reactive power provided at the load side. It is an open loop model result for the control of reactive power.

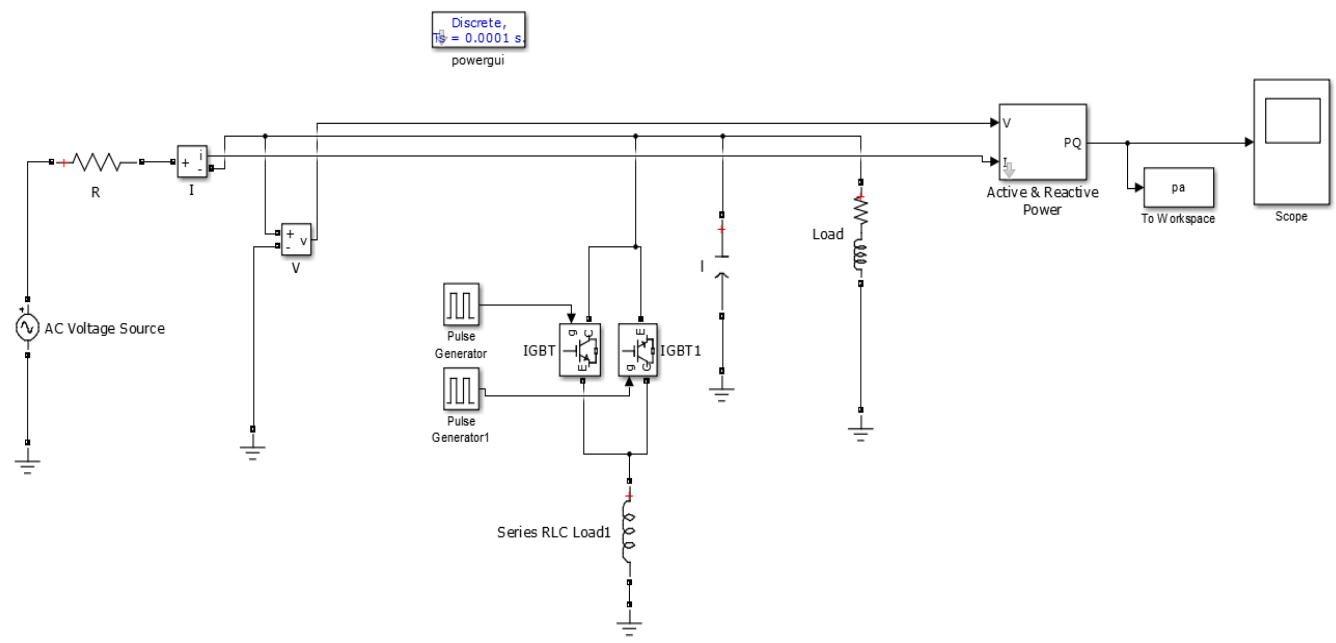

Figure 1 Simulink Model for Fixed Load 


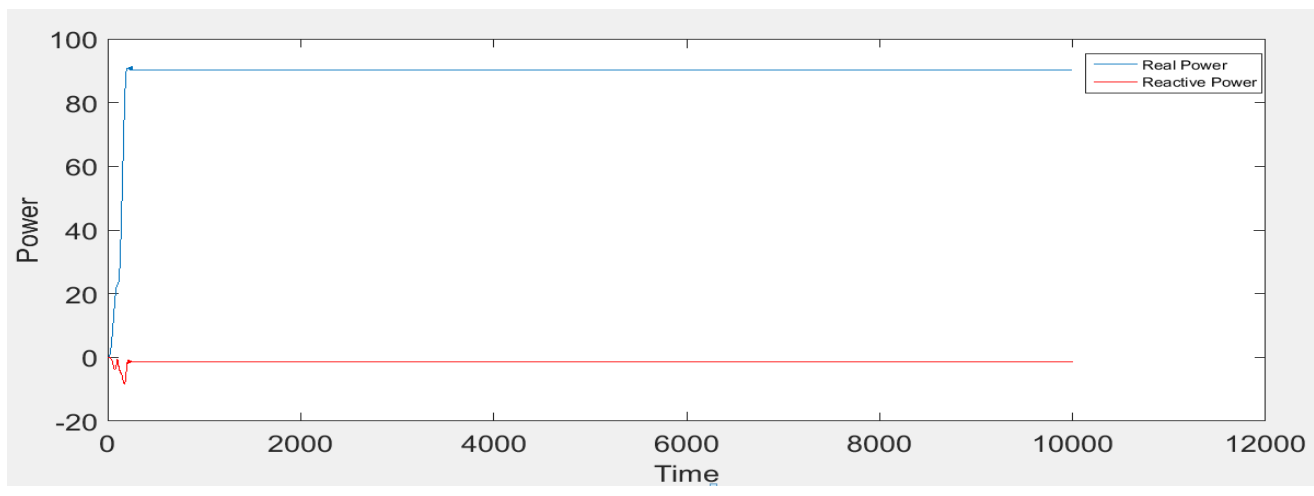

Figure 2 Simulation result for fixed load

\begin{tabular}{|l|l|}
\hline PULSE WIDTH IN \% & REACTIVE POWER \\
\hline 20 & -10.74 \\
\hline 20.5 & -8.70 \\
\hline 21 & -6.63 \\
\hline 21.5 & -4.45 \\
\hline 22 & -2.45 \\
\hline 22.5 & 0 \\
\hline 23 & 1.83 \\
\hline 23.5 & 3.97 \\
\hline 24 & 6.12 \\
\hline 24.5 & 8.26 \\
\hline 25 & 10.40 \\
\hline 50 & 50 \\
\hline
\end{tabular}

Table 1 Lookup Table

Table 1 shows the Value of reactive power supplied to the load changes, as we change the pulse width.

\subsection{Analysis of FC-TCR}

It is very important to decide the location of FACTS device before connecting to the system for determine its potency. Preferably, FACTS device should be connected at the electrical center of the system or midpoint of transmission line [2]. The limitation of TCR device is it deliver controllable reactive power only in lagging power factor range. So, that capacitor bank is connected in shunt with TCR to enlarge dynamic controllable range to the leading power factor range.

Figure 3 shows basic circuit of the FC-TCR type SVC. It consists of parallel connection of fixed capacitor and inductor with anti-parallel connected thyristor or IGBT valve.

Figure 4 shows voltage and current waveforms through a pure inductor.in a pure inductor, current legs the applied voltage by $90^{\circ}$. so we can control current between $90^{\circ}$ to $180^{\circ}$ in positive half cycle. So, the control range of FC-TCR is 900 to $180^{\circ}$ in positive half cycle and it is $270^{\circ}$ to $360^{\circ}$ in negative half cycle. 


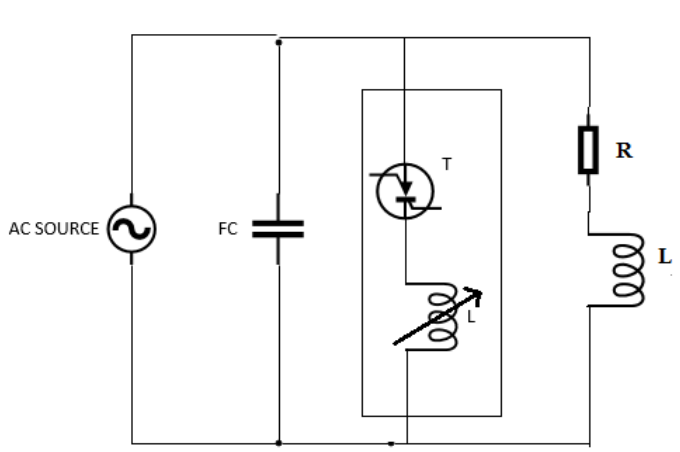

Figure 3 Basic Circuit of FC-TCR

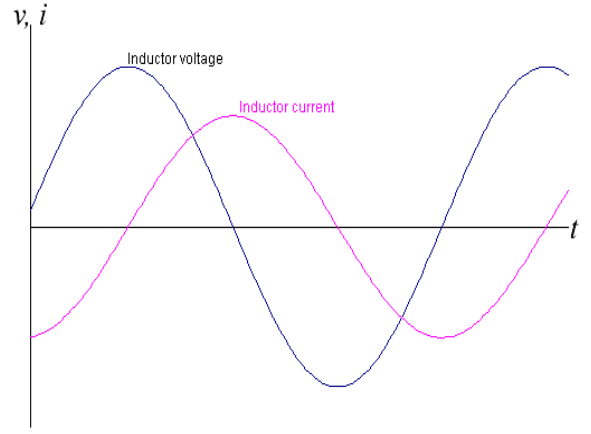

Figure 4 Control Range of FC-TCR

\section{Simulation and results analysis}

\subsection{Simulink Model}

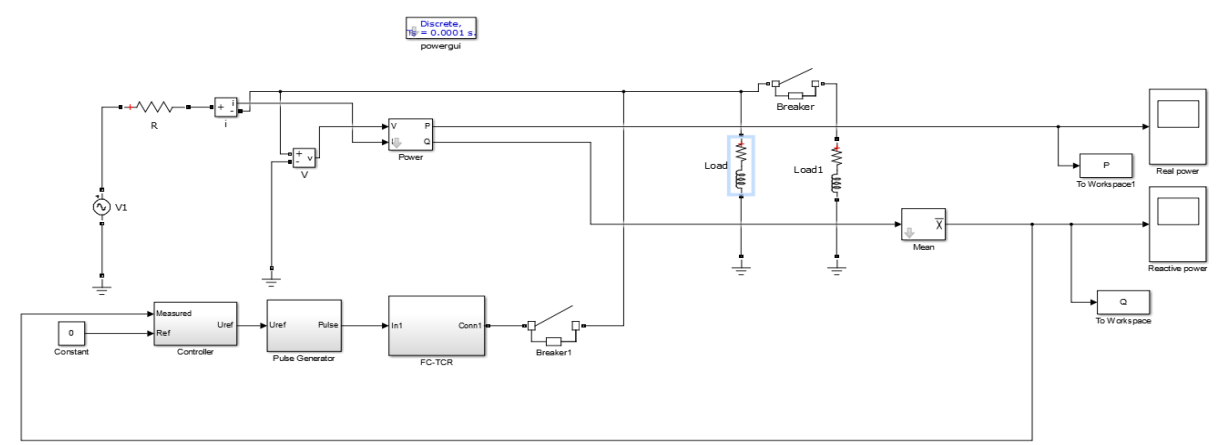

Figure 5 MATLAB Simulink model of FC-TCR with Controller

As shown in the Figure 5 variable RL load is connected in single phase line. Because of variable $\mathrm{RL}$ load requirement of the reactive power is also varies. So, by giving require reactive power through capacitor bank and by absorbing surplus reactive power through inductor we can compensate the reactive power. Here the value of the capacitor bank is fixed. And absorbing of the surplus reactive power is done by antiparallel connected thyristor switches, by controlling the firing angle or pulse width we can control the value of the reactor. The PI controller is being used here for the complete close loop control. The value of $\mathrm{P}$ and $\mathrm{I}$ are 0.005 and 0.00001 respectively. This value so selected give us proper control over the reactive power to be supplied to load.

\begin{tabular}{|l|l|}
\hline Parameters & Value \\
\hline 1. Source voltage & 1000 Volt \\
\hline 2. Resistance of line & $0.01 \mathrm{ohms}$ \\
\hline 3. Active Power Loading (Load) & $100 \mathrm{~W}$ \\
\hline 4. Active Power Loading (Load1) & $100 \mathrm{~W}$ \\
\hline
\end{tabular}




\begin{tabular}{|l|l|}
\hline 5. Reactive Power Loading (Load) & $100 \mathrm{VAR}$ \\
\hline 6. Reactive Power Loading(Load1) & $50 \mathrm{VAR}$ \\
\hline 7. Reactor Rating & $100 \mathrm{VAR}$ \\
\hline 8. Capacitor Rating & $150 \mathrm{VAR}$ \\
\hline
\end{tabular}

\subsection{Subsystems}

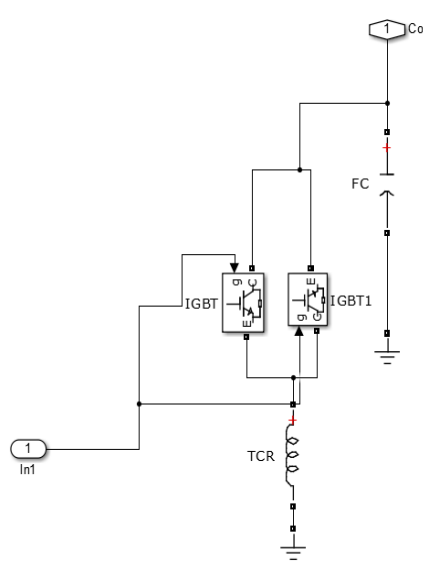

Figure 6 FC-TCR

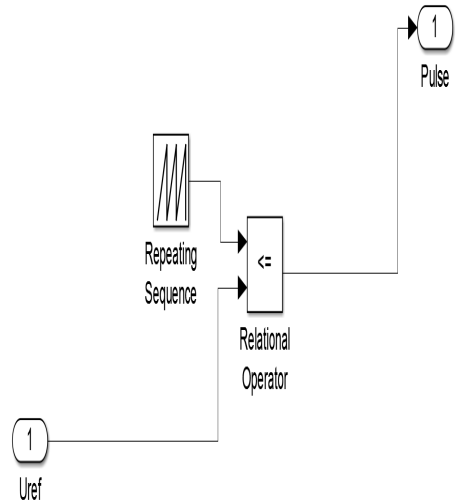

Figure 7 Pulse Generator

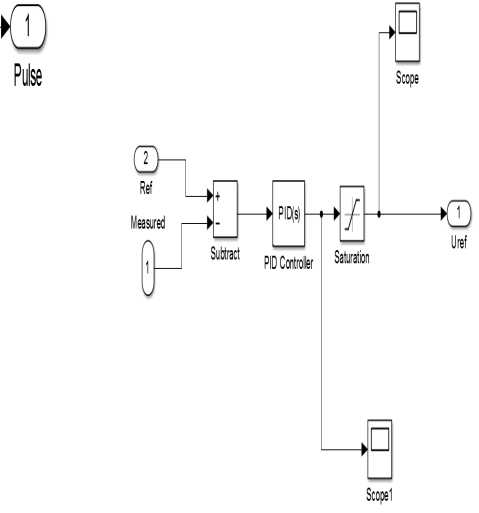

Figure 8 Controller Block

\subsection{Results}

The MATLAB-Simulink model is shown in Figure 5. As shown in model Fixed-Capacitor bank is connected in parallel to the load to compensate load reactive power near to zero. As this is variable RL load the requirement of reactive power is also varying as time changes. For that variable reactive power control TCR is provided with controller to provide automatic control.

Figure 9 is Simulink result of reactive power for variable load and its automatic control. From the result, it is seen that the device FC-TCR is introduce at 1 second. Before that the value of reactive power is $100 \mathrm{VAR}$ and after introducing FC-TCR value of reactive power is compensate and reduce to -20 VAR and value of Real power is also increase as reactive power is compensated. At time equals to 2 second load is change so further the value of reactive power further changes to $+30 \mathrm{VAR}$, but not goes to $100 \mathrm{VAR}$ because of automatic control of PI controlling block. 


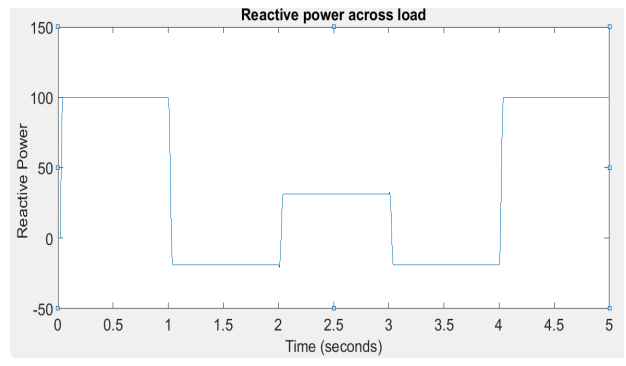

Figure 9 Compensated Variable Reactive Power Load

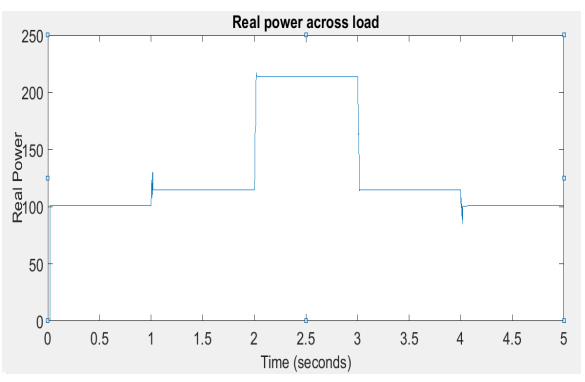

Figure 10 Real Power

\section{Conclusion}

- From simulation, we can conclude that introduction of the FC-TCR provides the required compensation for the demanded reactive power. Thus, compensating the requirement of the load.

- Control of the IGBT/switches by PI controller eliminates manual intervention leading to flexibility in control of reactive power.

- PI controller reduce the error by damping the oscillation and improving the output power quality.

\section{References}

Naring Hingorani, Laszlo Gyugyi, "Understanding FACTS “Standard Publishers Distributors, First Edition-2001

K.R. PADIYAR "FACTS controller in power transmission and distribution. "NEW AGE INTERNATIONAL(P) LIMITED, PUBLISHERS".

San-Yi Lee, Chi-Jui Wu, Wei-Nan Chang, "A compact control algorithm for reactive power compensation and load balancing with static Var compensator. "Electric Power Systems Research 58 (2001) 63-70, ELSEVIER

Kumar, Dr. Narendra Kumar, Vipin Jain, "Comparison of Various Auxiliary Signals for Damping Sub-Synchronous Oscillations Using TCR-FC." 2nd International Conference on Advances in Energy Engineering (ICAEE 2011), ELSEVIER

Yuval Beck, Yefim Berlovich, Arie Braunstein, "A Matlab-Simulink Model of AC Grid with a FCTCS and Invariant Control System for Reactive Power Compensation. "International Symposium on Power Electronics, Electrical Drives, Automation and Motion. IEEE 2016

AliReza Karami-Horestani, Mohamad Esmail Hamedani Golshan, Hamze Hajian-Hoseinabadi, "Reliability modeling of TCR-FC type SVC using Markov process." Electrical Power and Energy Systems 55 (2014) 305-311, ELSEVIER. 